\title{
SHARING GOODS? YUCK, NO! AN INVESTIGATION OF CONSUMERS' CONTAMINATION CONCERNS ABOUT ACCESS-BASED SERVICES
}

\author{
Simon HAZÉE ${ }^{1}$ \\ Yves VAN VAERENBERGH ${ }^{2}$ \\ Cécile DELCOURT ${ }^{1}$ \\ Luk WARLOP ${ }^{3}$
}

${ }^{1}$ HEC Liège, University of Liège, Belgium

${ }^{2}$ KU Leuven - University of Leuven, Belgium

${ }^{3}$ BI Norwegian Business School, Norway

Simon HAZÉE is the corresponding author. Contact information: Rue Louvrex, 14, 4000 Liège, Belgium, Tel.: +3242327225, E-mail: Simon.Hazee@uliege.be

Keywords: Access-Based Services, Sharing Economy, Contamination, Service Innovation, Innovation Adoption.

Acknowledgements: The authors would like to thank JSR's editor Mike Brady, the associate editor and three anonymous reviewers for their constructive feedback. We would also like to thank Annouk Lievens and Dwayne Gremler for reading and commenting on an earlier draft of this paper. 


\title{
Sharing Goods? Yuck, No! An Investigation of Consumers' Contamination Concerns
}

\section{About Access-Based Services}

\begin{abstract}
Although access-based services (ABS) offer many benefits, convincing consumers to use these service innovations remains challenging. Research suggests that contamination concerns are an important barrier to consumer adoption of ABS; they arise when a person believes someone else has touched an object and transferred residue or germs. However, systematic examination of this phenomenon is lacking. We conduct four experiments to determine (1) the impact of contamination concerns on consumer evaluations of ABS, (2) when such concerns become salient in ABS, and (3) how ABS providers can reduce these concerns. The results reveal that consumers experience more contamination concerns about objects used in proximity to their bodies, especially when those objects are shared with unfamiliar users, and that such concerns negatively influence their evaluations of ABS. Consumers also exhibit less contamination concerns about ABS that have high brand equity, because of their elevated stereotype-related perceptions of the competence of those users. Firms' advertisements depicting physical contact between shared objects and other users negatively influence ABS evaluations by consumers whose contamination concept is activated. This article provides insights for developing product, branding, and communication strategies to reduce consumers' contamination concerns and maximizing ABS adoption.
\end{abstract}

Keywords: Access-Based Services, Sharing Economy, Contamination, Contagion, Innovation Adoption. 


\section{INTRODUCTION}

"I would not like it ... putting my hands where everyone put theirs ... and you never know... The tissues, diseases, yuck no! There might be a guy who coughed on the steering wheel [of the shared car] the whole day, and then you must put your hands on it!'” (potential car-sharing user)

In this quote from Hazée, Delcourt, and Van Vaerenbergh (2017, p. 447), a consumer expresses concerns about accessing a potentially contaminated car through a car-sharing program. The consumer's comment exemplifies a fear of contamination, or contamination concerns, which occur when a consumer perceives that an object has been in physical contact with someone else and could have been soiled through the transfer of germs or residue (Nemeroff and Rozin 1994). Fear of contamination often is associated with unfavorable product evaluations and reduced purchase intentions (White et al. 2016).

Although contamination concerns can arise in various settings, the quote refers to accessbased services (ABS), defined as service innovations that provide consumers with temporary access to physical objects in return for access fees. In these arrangements, legal ownership of the goods remains with their owners, usually companies (Bardhi and Eckhardt 2012), but the users gain anonymous, short-term access to the goods on a self-service basis (Schaefers et al. 2016). Examples of ABS include car-sharing (e.g., Zipcar) and bike-sharing services (e.g., Cyclocity). Despite growing usage of ABS, it remains challenging for firms to convince consumers to use such services (Needleman and Loten 2014), such that firms clearly need new insights into how to overcome the barriers to ABS adoption (Hazée, Delcourt, and Van Vaerenbergh 2017). Specifically, firms need to understand consumers' perceived barriers to innovations in order to develop efficient strategies aimed at overcoming those barriers and boosting adoption rates (Martin, Gustafsson, and Choi 2016).

Although qualitative investigations of ABS imply that contamination concerns may represent an important psychological barrier (Bardhi and Eckhardt 2012; Hazée, Delcourt, and 
Van Vaerenbergh 2017), the notion has not been empirically tested. For example, a Time magazine cover article about the sharing economy (Stein 2015) highlights contamination concerns as a key barrier. Bardhi and Eckhardt (2012) reveal that consumers may experience feelings of disgust when sharing goods, which harm their ABS experiences. Hazée, Delcourt, and Van Vaerenbergh (2017) also propose that contamination concerns represent a unique psychological barrier that influences consumer evaluations of ABS, and Gullstrand Edbring, Lehner, and Mont (2016) suggest that fear of contamination is one of the most important obstacles to the adoption of ABS. Yet systematic empirical research into consumers' contamination concerns related to ABS is particularly lacking (Morales, Dahl, and Argo 2018), and three critical questions remain: What is the impact of contamination concerns on consumers' evaluations of ABS? When do consumers experience contamination concerns about ABS? How can ABS providers prevent consumers' contamination concerns and reduce their potentially negative effects?

Using contamination theory (Frazer [1890] 1959; Tylor [1871] 1974) as a theoretical anchor, we aim to address these questions. In doing so, we integrate contamination, innovation diffusion, and ABS streams of literature and contribute in three main ways. First, this study extends prior research on ABS adoption (e.g., Lamberton and Rose 2012; Lawson et al. 2016) by empirically demonstrating the negative effect of product contamination concerns on consumer evaluations of ABS. Second, prior research has studied general contamination cues, such as the number of sources who come in contact with a product, product packaging damage, and time elapsed since contact (Argo, Dahl, and Morales 2006; White et al. 2016); this study extends that research stream by addressing additional cues that predict ABS-related contamination concerns: (1) product-body proximity and (2) familiarity with other users. Third, this study responds to recent calls for more research on strategies for reducing consumer rejection of service innovations (e.g., Heidenreich and Kraemer 2016; Talke and Heidenreich 2014). To the best of the authors' knowledge, it is the first to provide empirical evidence for 
how specific organizational branding and communication actions influence consumers' contamination concerns in general and ABS adoption in particular. From a managerial perspective, this research shows that service providers must consider consumers' contamination concerns and suggests specific product, branding, and communication strategies to reduce them and boost adoption rates of ABS offerings.

\section{THEORETICAL BACKGROUND}

\section{Access-Based Services (ABS)}

Both technological advances and societal trends toward sustainability have contributed to the increasing popularity of ABS (Belk 2014). Even traditional businesses have begun to develop ABS as a servitization strategy (e.g., BMW's car-sharing program DriveNow), suggesting that we are entering a post-ownership economy (Belk 2014). Consumer adoption and usage of ABS depends on various factors, including transaction utility (i.e., good deals), price, perceived degree of substitutability between ownership and sharing, flexibility of the service, prior knowledge, product scarcity, and the technical costs associated with sharing (Claudy, Garcia, and O'Driscoll 2015; Lamberton and Rose 2012). Bardhi and Eckhardt (2012) show that carsharing increases consumers' personal utility, because they want to escape the burdens of ownership by reducing their financial expenses and increasing their personal convenience. Schaefers (2013) and Lawson et al. (2016) find that consumers' motivations for using ABS include economic and environmental consciousness, status associated with access, variety seeking, lifestyle, and materialistic values.

However, these insights into why people adopt cannot explain the lack of widespread acceptance of ABS in practice (Needleman and Loten 2014), which suggests that barriers remain (Schaefers 2013). In addition to product scarcity, status associated with access, and technical costs, Hazée, Delcourt, and Van Vaerenbergh (2017) suggest that fear of contamination is a key psychological barrier related to ABS. Contamination concerns appear 
particularly relevant in ABS contexts, for four reasons: (1) Consumers must touch the (potentially contaminated) shared objects, (2) consumers typically do not know who else has used the objects beforehand, (3) consumers do not know how previous consumers have used the shared objects, and (4) employees do not systematically check the shared objects after each consumer usage (Bardhi and Eckhardt 2012; Hazée, Delcourt, and Van Vaerenbergh 2017). Fear of contamination can be complex, powerful, and persistent (Rachman 2004), indicating the importance of investigating the role of contamination in ABS (Morales, Dahl, and Argo 2018).

\section{Product Contamination}

Contamination theory (Frazer [1890] 1959; Tylor [1871] 1974) posits that when a source and a target come into direct or indirect contact, people implicitly or explicitly experience the source transferring some or all of its properties to the target. Consumers can express both positive and negative responses to previously touched objects. Argo, Dahl, and Morales (2006) show that consumers are less likely to buy a T-shirt if another shopper has just tried it on (i.e., negative contamination) but more likely to purchase an object if it came into contact with an attractive or famous person (i.e., positive contamination). The processes underlying positive and negative contamination differ. Positive contamination is the result of a symbolic interaction model, associated with interpersonal and moral factors, and it involves magical beliefs (i.e., transfer of essence) (Nemeroff and Rozin 1994). People want to be associated with objects that have been in contact with someone about whom they have strong, positive feelings (e.g., a celebrity) (Newman, Diesendruck, and Bloom 2011).

Negative contamination also may result from a symbolic transfer (e.g., sweater worn by Hitler) (Nemeroff and Rozin 1994), but it is triggered mainly by beliefs about transfers of germs or toxic residue. Argo, Dahl, and Morales (2006) argue that the low desirability of second-hand products is not based on associations; the previous owners of the products are anonymous. Rather, it results from a belief about a potential transfer of residue or alien germs through 
product usage. Those who perceive contamination cues activate a disease-avoidance system (Griskevicius and Kenrick 2013) that motivates them to avoid potential contaminants, because such avoidance reduces their likelihood of being contaminated or harmed (Rachman 2004). Accordingly, this study develops hypotheses about specific contamination cues related to ABS and how firms' practices may influence such cues.

\section{HYPOTHESES DEVELOPMENT}

Figure 1 depicts the conceptual framework for this study. We propose that product-body proximity and interpersonal familiarity represent unique contamination cues in $\mathrm{ABS}$. We also propose that brand equity influences consumer concerns about product contamination in ABS, especially in relation to personal stereotypes about other users. Finally, we develop hypotheses with regard to the effects of traditional communications actions of firms (i.e., highlighting physical contact between shared objects and other users in advertisements) on consumers' contamination concerns and ABS evaluations.

\section{[FIGURE 1 HERE]}

\section{Negative Contamination in ABS}

Contamination theory suggests that those who experience contamination concerns try to avoid contaminants (Griskevicius and Kenrick 2013); consumers are less likely to buy second-hand products (e.g., Kapitan and Bhargave 2013) or demonstration products (e.g., Kotler and Mantrala 1985) if they are concerned about contamination. Contamination concerns also may have a negative influence on consumers' evaluations of products they wish to purchase and own (e.g., Argo, Dahl, and Morales 2006; Newman, Diesendruck, and Bloom 2011) or objects they wish to access (Hazée, Delcourt, and Van Vaerenbergh 2017). According to Gullstrand Edbring, Lehner, and Mont (2016), contamination is the second most important obstacle to consumer adoption of ABS. Accordingly, we hypothesize: 
H1. Consumers' contamination concerns negatively influence their attitudes and usage intentions related to ABS.

\section{Roles of Product-Body Proximity and Interpersonal Familiarity}

Product-Body Proximity. Contamination concerns are strongly linked to disgust (e.g., Argo, Dahl, and Morales 2006; Morales and Fitzsimons 2007); both can trigger defense mechanisms against the penetration of substances into one's body or revulsion responses to offensive objects (Rozin and Fallon 1987). Disgust is associated with food; it focuses on the mouth and ingestion (Rozin, Haidt, and McCauley 2008). Disgust and contamination concerns therefore appear greater for products that typically are used in close contact with the body (Rozin and Fallon 1987). These effects are especially salient for products that are ingested; oral incorporation is one of the most intimate forms of contact (Castro, Morales, and Nowlis 2013) and is more likely than mere use to result in disease (Rozin, Haidt, and McCauley 2008).

Prior research on negative contamination has focused on consumable (e.g., juice) versus non-consumable (e.g., fabric softener) products (Castro, Morales, and Nowlis 2013). In ABS contexts, even though shared objects (e.g., cars, bikes, garden tools) are not ingested, we argue that some have stronger associations with oral contact than others. Consumers' mind associations typically affect their behaviors (Krishnan 1996), so we predict that product associations with ingestion trigger contamination concerns (Krishnan 1996). That is, the negative effects of contamination concerns should be stronger when the non-consumable, tangible objects being accessed are associated with oral incorporation or used in proximity to the body, whereas the negative effects should be weaker for objects that are not associated with ingestion or are distant from the body. We hypothesize:

H2. For ABS, consumers exhibit more negative contamination concerns about products used in proximity versus products used distant from their bodies.

Interpersonal Familiarity. Drawing on prior research on consumer contamination cues (e.g., Argo, Dahl, and Morales 2006; Morales and Fitzsimons 2007; White et al. 2016), we also argue 
that contamination concerns depend on the nature of the source that comes in contact with the product. This expectation is consistent with studies that show that positive contamination is likely when the product was touched by an attractive person (Argo, Dahl, and Morales 2008) or a celebrity (Newman, Diesendruck, and Bloom 2011). Extending this finding to negative contamination, we expect that negative contamination effects differ, depending on who touched the objects available to consumers via ABS.

Consumers of ABS may share objects with people with whom they are familiar (e.g., neighbors) or people they do not know personally (Bardhi and Eckhardt 2012). The lack of familiarity with other users may influence how consumers behave (Schaefers et al. 2016). Therefore, companies such as Zipcar tend to highlight the local aspect of their sharing initiatives (“Zipcar makes great neighbors"), to increase perceived familiarity with other users. Selfcategorization theory (Turner et al. 1987) posits that people define themselves in terms of group membership; they consider familiar group members to be part of their extended selves. Social psychology uses self-categorization theory to show that disgust keeps groups apart; it may invoke extreme forms of prejudice against out-group members, to protect in-group members from outside threats (e.g., Taylor 2007). Familiar others do not represent potential threats, or contaminants, to the self (Reicher et al. 2016; Rozin, Haidt, and McCauley 2008). Accordingly, we predict that the level of familiarity with other ABS users moderates the effects of productbody proximity on contamination concerns; so when consumers share objects with familiar (unfamiliar) users, they should have less (more) contamination concerns for products used in proximity to their bodies. We hypothesize:

H3. The level of familiarity with other ABS users moderates the effect of productbody proximity on consumer contamination concerns, such that as the level of familiarity increases, the positive effect of product-body proximity on consumer contamination concerns is attenuated.

\section{Roles of Brand Equity and Stereotypes}


Drawing on signaling theory (Spence 1974), researchers have suggested that signals related to branding effectively overcome consumer-perceived barriers (e.g., Corkindale and Belder 2009; Henard and Dacin 2010). In this study, we accordingly propose that brand equity influences the contamination barrier, by activating consumers' stereotypes about other ABS users. Stereotypes are consumers' "beliefs about the traits of people based on their use of product or brands that result in inferential self- and other judgments" (Pechman and Knight 2002, p. 5). They guide people's social judgments and actions (Greenwald and Banaji 1995); for example, consumers might avoid products or brands linked to negatively viewed social groups (e.g., Berger and Heath 2008). Two dimensions capture differences across stereotypes: competence and warmth (Fiske et al. 2002). Competence judgments include perceptions of confidence, effectiveness, and intelligence, and warmth judgments include perceptions of generosity, kindness, and honesty (Aaker, Vohs, and Mogilner 2010; Fiske et al. 2002).

According to the stereotyping literature, being judged as competent is linked to being seen as high in status (Fiske et al. 2002). High levels of competence signal consumers that companies offer high quality services (Aaker, Vohs, and Mogilner 2010; Goldsmith, Lafferty, and Newell 2000). On the other hand, being seen as high in warmth — even though positivedoes not guarantee high-quality service delivery. For instance, Aaker, Vohs, and Mogilner (2010) show that consumers are more likely to buy products from companies that trigger perceptions of competence. Further evidence also shows that warmth stereotypes influence consumer evaluations, yet only when companies are already perceived as competent (Grandey et al. 2005). The effects of competence stereotypes are seven times stronger than the effects of warmth stereotypes on consumer outcomes (Aaker, Vohs, and Mogilner 2010). Building on these findings, we posit that, in general, competence stereotypes will influence consumer contamination concerns about ABS, whereas warmth stereotypes will not.

In marketing, signaling actions may prime specific stereotypes. For example, brand equity - the strength of a brand in consumers' minds, in terms of brand awareness, perceived 
quality, and other brand assets (Aaker 1991) - is a signaling phenomenon that can trigger stereotypes (Darke and Ritchie 2007). Consumers of high-equity brands are perceived as more competent than consumers of low-equity brands; brand perceptions may indeed carry over and affect consumers' perceptions of brands' actual consumers, through a process of impression formation (Fennis and Pruyn 2007). Contamination concerns depend on the nature of the source that comes in contact with the object. Sources associated with positive attributes are less likely to result in contamination concerns than sources associated with negative attributes (Argo, Dahl, and Morales 2008; Rozin, Haidt, and McCauley 2008). Consumers of ABS usually do not have any contact with other users (Bardhi and Eckhardt 2012), so they may draw inferences about the nature of other users, based on available information (e.g., signaling cues such as perceived brand equity of offers). This information ultimately influences the degree of their contamination concerns. Accordingly, we expect that ABS consumers exhibit less contamination concerns about high brand equity access offers, due to their elevated perceptions of competence associated with users who have touched the shared objects. Therefore, we hypothesize:

H4a. Consumers exhibit less negative contamination concerns about ABS with high versus low brand equity.

$H 4 b$. Consumers' stereotype-related perceptions of competence associated with other ABS users mediate the effect of brand equity on contamination concerns.

\section{Roles of Firms' Communication Practices and Interpersonal Similarity}

Incidence of Physical Contact Depiction in ABS Advertising. In addition to taking branding actions, firms can engage in various communication tactics to reduce the uncertainty associated with innovation adoption (Heidenreich and Kraemer 2016). For example, communicating that an innovation belongs to a certain product category reduces consumers' perceptions of the complexity of the innovation (Goode, Dahl, and Moreau 2013). Helping consumers visualize the new usage situation through advertisements is also considered as an effective 
communication instrument to reduce consumer rejection of the innovation (Heidenreich and Handrich 2015).

Given the difficulty for consumers to assess service quality prior to purchase (Parasuraman, Zeithaml, and Berry 1985), service organizations must clearly and unambiguously communicate the benefits of their offerings (Hill et al. 2004). However, if communication that emphasizes physical contact between products and other consumers results in negative outcomes, especially for potential consumers whose contamination concepts get unintentionally activated during the consumer journey (Bargh et al. 2001) or who have a natural high level of disgust sensitivity (Rozin, Haidt, and McCauley 2008), firms must carefully frame the information and use appropriate pictorial stimuli to reduce the potentially negative effects of contamination concerns.

Service providers often use visual strategies to communicate the benefits of their offerings (Hill et al. 2004). Leading car-sharing companies use advertising images that depict people using (and therefore touching) their cars, for example. Although pictorial stimuli are considered more effective than text alone (Rossiter and Percy 1980), we argue that if they seek to help consumers understand the benefits of service innovations and reduce rejection (Zhao, Hoeffer, and Zauberman 2011), ABS providers may need to avoid using images that highlight physical contact between products and consumers to reduce the detrimental effects of contamination concerns. We hypothesize:

H5. Advertisements that display high incidences of physical contact negatively influence consumers' evaluations of ABS.

Interpersonal Similarity. Firms need to influence and manage social distance, including through advertising, to enhance connections with and between consumers (Edwards, Lee, and La Ferle 2009). In addition to familiarity perceptions, interpersonal similarity is another way that individuals may use to evaluate social distance. Prior research distinguishes interpersonal similarity — be it in attitudes, values, or background variables - from interpersonal familiarity, 
which is determined by the frequency of prior encounters with other people (Dubé and Schmitt 1999; Edwards, Lee, and La Ferle 2009). Similarity and familiarity are distinct, yet related concepts. In particular, similarity may influence familiarity perceptions both directly and indirectly. On one hand, people who encounter similar others are reminded of themselves and past experiences, which would produce a sort of "halo effect" and influence the extent to which they consider others as familiar. On the other hand, people might overestimate the number of prior interactions with similar others, and thus their familiarity, because of attraction feelings (Moreland and Zajonc 1982).

Consumers of ABS may not only share objects with people with whom they are familiar, but also with people they consider as similar to themselves. Similar others are commonly perceived as socially closer to oneself compared to dissimilar ones (Liviatan, Trope, and Liberman 2008). Other ABS users who are similar tend to be regarded as in-group membersand therefore less likely to be sources of contamination (Reicher et al. 2016; Rozin, Haidt, and McCauley 2008). Given these observations, we expect that interpersonal similarity would moderate the detrimental effects of images highlighting physical contacts between products and consumers. More formally, we hypothesize the following:

H6. The level of similarity with other users moderates the effect of ABS advertisements displaying physical contacts on consumer evaluations, such that, as the level of interpersonal similarity increases, the negative effect of physical contact depiction on consumer evaluations is attenuated.

\section{OVERVIEW OF STUDIES}

To test our hypotheses, we present four studies (see Figure 1) in different ABS contexts. In Study 1, we use a priming technique to empirically test the assumption that consumers with salient contamination concerns are less likely to adopt and use ABS. In Study 2, we determine when ABS consumers experience negative contamination concerns by examining the roles of 
product-body proximity and familiarity with other users. In Study 3, we investigate the impact of brand equity on consumers' contamination concerns, and we test its mediation through stereotypes associated with other ABS users. Finally, in Study 4, we investigate the effects of physical contact displayed through advertisements on the ABS evaluations of those whose contamination concepts have been activated, and then we test for the moderating role of interpersonal similarity.

\section{STUDY 1}

\section{Method}

Data. A priori sample size calculations reveal a minimum sample size of 90 participants to test the hypotheses (see the Web Appendix for further explanations). We used Amazon Mechanical (MTurk) to recruit 124 participants. This online subject pool offers a source of reliable data, representative of the general population (Crump, McDonnell, and Gureckis 2013; Goodman and Paolacci 2017). Respondents received US \$0.3 in exchange for their participation. In line with Dong et al.'s (2015) procedure, we removed participants who exhibited issues, such as very short completion times, large amounts of missing data, failure of a basic attention check (i.e., "If you read this statement, tick the box 'Strongly Agree'"), or failure to complete the priming task. In addition, following Sharpe Wessling, Huber, and Netzer's (2017) recommendations, we paid all respondents (without screening) to avoid misrepresentation, then removed non-U.S. respondents from subsequent analyses (according to both self-determined nationality and IP addresses). This screening helped ensure that all respondents had high English proficiency. The final sample consisted of 112 U.S. respondents $\left(\mathrm{M}_{\mathrm{age}}=35, \mathrm{Min}_{\mathrm{age}}=\right.$ $19, \operatorname{Max}_{\mathrm{age}}=66 ; 47 \%$ female $)$.

Procedure and Measures. Respondents were asked to participate in a two-condition (contamination prime: absent vs. present) between-subjects experiment; the cell sizes were 55 and 57, respectively. We chose car-sharing as the research context, given its prevalence in the 
United States (Lawson et al. 2016). In line with Chartrand et al. (2008), we asked respondents to engage in a scrambled-sentence task. They first constructed grammatically correct sentences using four of six scrambled words. For the contamination-present group, words invoking disease-avoidance appeared in the list (e.g., "he," "disease," "what," "avoided," "want," "did"; the solution is "what did he want"). This task was designed to influence respondents' behavior by activating the contamination concept in their minds (Griskevicius and Kenrick 2013). For the control group, the list contained neutral words adopted from Doyen et al. (2012) (e.g., "he," “empirical," "what," "presented," "want," "did;" with the same solution). After completing a 5-minute filler task, respondents read a description of a typical car-sharing service (see Web Appendix), then rated their intentions to use the service $(\alpha=.86)$ and their attitudes toward it ( $\alpha=.97)$, on three-item, 7-point scales adopted from Maxham and Netemeyer (2002) and Dabholkar and Bagozzi (2002), respectively.

\section{Results}

Manipulation Check. In line with prior research (e.g., Brady et al. 2008), we checked the contamination manipulation in a separate pilot study with 61 participants. In doing so, we could avoid psychological (e.g., response bias such as demand characteristics) as well as analytical issues (e.g., measurement errors) commonly associated with manipulation checks (e.g., Hauser, Ellsworth, and Gonzalez 2018; Perdue and Summers 1986). Contamination concerns were assessed using a 5-point scale adapted from Castro, Morales, and Nowlis (2013) and Newman, Diesendruck, and Bloom (2011) (e.g., "To what extent would you worry about using this product if someone else had touched it?"). Results show that the contamination manipulation worked as intended. In particular, participants had more contamination concerns in the contamination-present condition $(\mathrm{M}=3.63, \mathrm{SD}=1.82)$ than in the contamination-absent condition $(\mathrm{M}=2.25, \mathrm{SD}=1.44 ; t(59)=3.28, p=.002)$.

Study Results. The results of a multivariate analysis of variance (MANOVA) indicate a significant impact of contamination priming on both attitudes and usage intentions at the 
multivariate level (Wilks' lambda $\left.=.95, F(2,109)=3.12, p=.048, \omega_{p}^{2}=.036\right)$. At the univariate level, goal priming has significant effects on consumer attitudes $(F(1,110)=5.72, p$ $\left.=.018, \omega_{p}^{2}=.040\right)$ and usage intentions $\left(F(1,110)=5.26, p=.024, \omega_{p}^{2}=.037\right)$. Consumers in the contamination-present condition express lower attitudes $(\mathrm{M}=4.54, \mathrm{SD}=1.63)$ and intentions to use $\mathrm{ABS}(\mathrm{M}=3.85, \mathrm{SD}=1.67)$ than consumers in the control condition (attitudes: $\mathrm{M}=5.25, \mathrm{SD}=1.50$; intentions: $\mathrm{M}=4.57, \mathrm{SD}=1.66)^{1}$, in support of $\mathrm{H} 1$.

\section{Discussion}

Study 1 empirically confirms prior (qualitative) findings that consumers high in contamination concerns are less likely to adopt and use ABS (Hazée, Delcourt, and Van Vaerenbergh 2017). These findings highlight the need to understand when contamination concerns about ABS occur. Study 2 thus examines the effects of specific cues, namely product-body proximity and familiarity with other ABS users.

\section{STUDY 2}

\section{Method}

Data. Following a priori sample size calculations (required minimum sample size: 333 ) and acknowledging issues commonly associated with data collection on Amazon MTurk, we oversampled and recruited 468 participants. Respondents received US\$0.30 in return for their participation. We excluded 29 participants from the study for the same issues described in Study 1. The final sample consisted of 439 participants, ranging in age from 19 to 70 years, with an average of 36 years; $49 \%$ were women.

Procedure and Measures. We asked respondents to participate in a 2 (product-body proximity: close vs. distant) $\times 3$ (interpersonal familiarity: low vs. moderate vs. high) betweenparticipants experimental design. Cell sizes ranged from 64 to 81 . Participants had to imagine needing a specific object for some reason, which they did not own. To manipulate productbody proximity, we identified two distinct objects that typically are available through ABS and 
associated (or not) with food consumption, a very intimate form of contact (Castro, Morales, and Nowlis 2013): a cheese fondue set (proximal) and a sander (distal).

Following the manipulation of product proximity, we told participants that one option would be to use ABS and share the object, with a friend (high familiarity condition), a close neighbor (moderate familiarity condition), or someone they did not personally know (low familiarity condition). Respondents rated their contamination concerns next, on a four-item scale $(\alpha=.95)$ adapted from Castro, Morales, and Nowlis (2013) and Newman, Diesendruck, and Bloom (2011), with the following items: "To what extent would you be concerned about someone else touching the product you were going to use?"; “To what extent would you worry about using this product if someone else had touched it?"; "I would be concerned about getting a disease when using this product."; "Touching this product would be a concern to me."

\section{Results}

Manipulation Checks. The manipulations for product-body proximity and interpersonal familiarity were checked in two separate pilot studies. In the first pilot study, we asked 51 respondents to evaluate their product-body proximity perceptions for the two objects, using a three-item, 5-point scale (e.g., "To what extent do you associate [object] with food consumption?"). The results confirmed that a cheese fondue set $(\mathrm{M}=4.80, \mathrm{SD}=1.27)$ was associated more with food consumption and oral ingestion than the sander $(\mathrm{M}=2.27, \mathrm{SD}=$ $1.41 ; t(49)=6.63, p<.001)$. In the second pilot study, 91 respondents rated their familiarity perceptions on a 7-point scale, using items adapted from Oliver and Bearden (1985) (e.g., "To what extent would you consider yourself familiar with this person?"). Results indicated that, as expected, respondents had higher familiarity perceptions when sharing an object with a friend $(\mathrm{M}=5.00, \mathrm{SD}=1.29)$, compared with a neighbor $(\mathrm{M}=3.95, \mathrm{SD}=1.51 ; F(88)=7.32, p=.008)$ and a stranger $(\mathrm{M}=3.08, \mathrm{SD}=1.88 ; F(88)=21.86, p<.001)$. The difference between the latter two conditions was also significant $(F(88)=4.62, p=.034)$. 
Study Results. A 2 (product-body proximity: proximal vs. distal) $\times 3$ (interpersonal familiarity level: low vs. moderate vs. high) analysis of variance (ANOVA) tested the effects of product-body proximity and familiarity with other users on consumers' contamination concerns. The results indicate significant main effects of both product-body proximity $(F(1$, $\left.433)=73.89, p<.001, \omega_{p}^{2}=.144\right)$ and familiarity with other users $(F(2,433)=7.46, p=.001$, $\left.\omega_{p}^{2}=.029\right)$. Consistent with $\mathrm{H} 2$, participants experience more contamination concerns about products used in proximity (cheese fondue set; $\mathrm{M}=3.46, \mathrm{SD}=1.88$ ) versus products used distant from their bodies (sander; $\mathrm{M}=2.09, \mathrm{SD}=1.51, p<001$ ).

The interaction effect between product-body proximity and familiarity with other users on respondents' contamination concerns also is significant $\left(F(2,433)=5.85, p=.003, \omega_{p}^{2}=\right.$ .022; see Figure 2). Follow-up tests reveal that in the distal condition, no significant differences in contamination concerns emerge among the high $(\mathrm{M}=1.83, \mathrm{SD}=1.29)$, moderate $(\mathrm{M}=2.35$, $\mathrm{SD}=1.69)$, and low $(\mathrm{M}=2.07, \mathrm{SD}=1.49 ; p \mathrm{~s}>.05)$ familiarity conditions. Participants in the proximal condition reported significantly more contamination concerns in the low familiarity condition $(\mathrm{M}=4.21, \mathrm{SD}=1.63)$ than in the moderate $(\mathrm{M}=3.21, \mathrm{SD}=1.95 ; p<.001)$ and high $(\mathrm{M}=2.94, \mathrm{SD}=1.72 ; p<.001)$ conditions; no significant differences arise between the latter two conditions $(p>.05)$. These findings support H3.

\section{[FIGURE 2 HERE]}

\section{Discussion}

Study 2 indicates that both product-body proximity and familiarity with other users influence consumers' contamination concerns about ABS. They exhibit more contamination concerns toward objects used in proximity to their bodies, especially when those objects are shared with unfamiliar users. When the objects are used more distantly from their bodies, consumers exhibit less contamination concerns, regardless of the level of familiarity with the other source that

came into contact with the object. Prior contamination research shows that consumable, ingestible products are more likely to trigger contamination concerns than non-ingestible ones 
(e.g., Castro, Morales, and Nowlis 2013), and our results indicate that the association with ingestion is already sufficient to trigger contamination concerns. In the next study, we investigate the role of organizational branding actions and specifically the effects of brand equity and stereotypes.

\section{STUDY 3}

\section{Method}

Data. Following a priori sample size calculations (required minimum sample size: 222), we recruited 308 participants on Prolific, an alternative to Amazon MTurk. Respondents received $£ 1.00$ in return for their participation. We excluded 12 participants from the analysis because of the reasons described in Study 1. The final sample consisted of 296 participants from the UK, ranging in age from 19 to 67 years, with an average of 38 years; $55 \%$ were women, and the cell sizes ranged from 73 to 75 .

Procedure and Measures. We asked respondents to participate in a 2 (product-body proximity: proximal vs. distal) $\times 2$ (brand equity: high vs. low) between-subjects experiment. Participants were randomly assigned to one of the four experimental conditions. They were first asked to imagine needing a specific product (either a travel cooler [proximal], or a power drill [distal]) and receiving a promotional leaflet about an ABS that provides access to this product. After presenting the benefits of adopting and using this service, we manipulated brand equity using Brady et al.'s (2008) procedure and by instruction, rather than according to consumers' experience with real brands, to avoid confounding effects and overcome a potential lack of knowledge about the brand equity construct or actual ABS providers. In the high brand equity condition, we told participants that the brand was well known worldwide, and though they were not experienced with it, they could imagine that they knew the brand name and were familiar with its image as a quality service provider. In the low brand equity condition, we informed 
respondents that the brand was not well known, and they were not familiar with the brand or its image.

Next, we asked respondents to rate their degrees of contamination concerns $(\alpha=.89)$ using the same scale used in Study 2. We measured their perceptions of competence $(\alpha=.90)$ and warmth $(\alpha=.90)$ about other users on three-item, 7-point scales adopted from Aaker, Vohs, and Mogilner (2010).

\section{Results}

Manipulation Check. The manipulation for brand equity was checked in pilot research with 55 respondents. Brand equity was assessed using a 7-point scale adapted from Brady et al. (2008) (e.g., "What kind of image does this service provider have?"). As expected, the results confirmed that the equity attached to the brand in the low-equity condition was lower $(\mathrm{M}=$ $3.97, \mathrm{SD}=1.68)$ than in the high-equity condition $(\mathrm{M}=5.21, \mathrm{SD}=1.20 ; t(53)=3.16, p=.003)$. Following Hauser, Ellsworth, and Gonzalez (2018), we do not check the product-body proximity manipulation in this pilot study as a similar procedure was used (and checked on a similar sample) in Study 2.

Study Results. The results of a 2 (product-body proximity: proximal vs. distal) $\times 2$ (brandequity level: high vs. low) ANOVA with contamination concerns as the dependent variable ${ }^{2}$ revealed a significant main effect of product-body proximity $\left(F(1,291)=139.41, p<.001, \omega_{p}^{2}\right.$ $=.32)$ and a marginally significant effect of brand equity $\left(F(1,291)=3.56, p=.060, \omega_{p}^{2}=.01\right)$ on respondents' contamination concerns about ABS. No significant interaction effect arises between product-body proximity and brand equity $(F(1,291)=1.47, p>.1)$. Consistent with $\mathrm{H} 2$, participants experienced more contamination concerns when they used the product in proximity to (association with oral consumption present; $\mathrm{M}=3.83, \mathrm{SE}=.11$ ) versus distant from $(\mathrm{M}=1.95, \mathrm{SE}=.11)$ their bodies. They also expressed less contamination concerns in the high brand equity condition $(\mathrm{M}=2.74, \mathrm{SE}=.11)$ than in the low brand equity condition $(\mathrm{M}=$ 3.04, $\mathrm{SE}=.11)$, in support of $\mathrm{H} 4 \mathrm{a}$. 
The results of another ANOVA show that brand equity significantly affects competence stereotypes $\left(F(1,293)=7.71, p=.006, \omega_{p}^{2}=.022 ; \mathrm{M}_{\text {high }}=4.84, \mathrm{SD}=.95 ; \mathrm{M}_{\text {low }}=4.50, \mathrm{SD}=\right.$ 1.11). We use PROCESS Model 4 (with 5,000 bootstraps) (Hayes 2013) to test the mediating role of competence stereotypes in the relationship between brand equity and contamination concerns. As anticipated, stereotype-related competence perceptions significantly predict contamination concerns $\left(B=-.33, \mathrm{SE}=.09, \mathrm{CI}_{95}:[-.51,-.16]\right)$ and mediate the effect of brand equity on contamination concerns $\left(B=-.11, \mathrm{SE}=.06, \mathrm{CI}_{95}:[-.25,-.03]\right)$. These results support H4b. To rule out an alternative explanation, namely, that stereotype-related associations of warmth also underlie the relationship between brand equity and contamination concerns, we ran a multiple mediator model with both competence and warmth as mediators. In line with our hypothesis, we find that competence stereotypes mediate this relationship $(B=-.11, \mathrm{SE}=.07$, CI95: [-.27, -.005]), but warmth does not $\left(B=.007, \mathrm{SE}=.06, \mathrm{CI}_{95}:[-.13, .13]\right)$.

\section{Discussion}

Overall, we find that brand equity can be used to reduce consumer contamination concerns, regardless of the product-body proximity. In particular, consumers of high-equity ABS brands exhibit less contamination concerns, because they consider other users to be more competent. Moreover, we find consistent results with regard to the effects of product-body proximity on contamination, replicating Study 2.

In addition to taking branding actions, firms can engage in various communication practices to influence consumer-perceived barriers and minimize consumer rejection of their innovations. Accordingly, in the following study, we examine how specific advertising actions (i.e., physical contact incidence and similarity highlighted in pictorial stimuli and selling messages) influence the ABS evaluations of consumers whose contamination concept has been activated. Prior research suggests that specific concepts and goals can be incidentally and unconsciously activated during the consumer journey (Bargh et al. 2001), which then influence how consumers behave and make decisions (Chartrand et al. 2008). Accordingly, our main 
objective in Study 4 is to examine whether firms can use marketing tools to encourage consumers whose contamination concepts have been activated to use ABS.

\section{STUDY 4}

\section{Method}

Data. Following a priori sample size calculations (required minimum sample size: 180), we invited 198 MBA students from a major Belgian university $\left(51 \%\right.$ women, 3 no report; $\mathrm{M}_{\mathrm{age}}=$ 21 years) to participate in a 2 (physical contact incidence: low vs. high) $\times 2$ (interpersonal similarity: present vs. absent) between-subjects experiment, with the contamination concept consistently activated across conditions. Cell sizes ranged from 49 to 50 . We recruited participants in class, before the start of a lecture. We chose car-sharing as a research context for three reasons: (1) Car-sharing solutions already existed in the city prior to the data collection, ensuring participants' familiarity with the concept; (2) university students are prospective customers of car-sharing services; and (3) a new car-sharing solution was about to be launched in the city at the time of the data collection, in line with our cover story.

Procedure and Measures. We told participants that an ABS provider was about to launch a new car-sharing service in their city and that the company wanted to get consumer feedback about its upcoming advertising campaign. We asked them to read a description of a typical carsharing service (see Web Appendix) and to complete a reflection exercise, supposedly to focus their attention. We included a prime of contamination concerns in this reflection exercise. All respondents engaged in a scrambled-sentence task that included words related to contamination and disease avoidance, as in Study 1.

After they completed a 5-minute filler task, we asked the respondents to view an advertisement from the car-sharing company (see Web Appendix). In the high contact incidence condition, the advertisement showed a hand touching the steering wheel, but there was no hand depicted in the low contact condition. In addition, the selling point emphasized the sustainable 
benefits of car-sharing, by highlighting either the average number of consumers driving (and therefore touching) the same car (high contact incidence condition) or the number of private cars taken off the road due to the service (low contact incidence condition). The advertisements' designs and numbers were identical across conditions. In the similarity-present condition, the commercial message also highlighted the similarity of other users ("drivers from the University" or "cars taken off the University campus roads"), but no such information appeared in the similarity-absent condition.

After completing this task, participants answered questions about their intentions to use the service $(\alpha=.80)$ and attitudes toward the service $(\alpha=.80)$. Their answers were measured on three-item, 7-point scales adopted from Maxham and Netemeyer (2002) and Dabholkar and Bagozzi (2002), respectively. They also answered basic questions about the advertisement, including their liking of the colors and design, to fit our cover story.

\section{Results}

Manipulation Checks. The manipulations for physical contact salience and interpersonal similarity were checked in a pilot study with 112 respondents. We assessed physical contact salience and interpersonal similarity using items adapted from existing scales (e.g., Desai and Keller 2002) (e.g., "The cars are very likely to be touched by someone else"; "The consumers of this car-sharing service are similar to me"). As expected, results for the physical contact salience manipulation indicated that the probability of physical contact is considered as higher in the high-contact salience conditions $(\mathrm{M}=6.22, \mathrm{SD}=.93)$ than in the low-contact salience condition $(\mathrm{M}=4.94, \mathrm{SD}=1.22 ; t(110)=6.26, p<.001)$. Results for the interpersonal similarity manipulation indicated that respondents had higher similarity perceptions in the similaritypresent condition $(\mathrm{M}=5.34, \mathrm{SD}=.82)$ than in the similarity-absent condition $(\mathrm{M}=4.63, \mathrm{SD}=$ $1.38 ; t(110)=3.19, p=.002)$.

Study Results. The results of a 2 (physical contact salience: low vs. high) $\times 2$ (interpersonal similarity: present vs. absent) MANOVA reveal the predicted two-way 
interaction effect on both attitudes and intentions to use ABS at the multivariate level (Wilks' lambda $\left.=.96, F(2,191)=3.37, p=.036, \omega_{p}^{2}=.024\right)$. At the univariate level ${ }^{3}$, we uncover a significant interaction effect on consumer attitudes $\left(F(1,192)=5.67, p=.018, \omega_{p}^{2}=.024\right)$ and usage intentions $\left(F(1,192)=3.92, p=.049, \omega_{p}^{2}=.015\right.$; see Figure 3). As anticipated, without any information about other users (similarity-absent condition), participants evaluated ABS more negatively when the advertisement established high (attitudes: $\mathrm{M}=4.84, \mathrm{SD}=1.06$; intentions: $\mathrm{M}=3.95, \mathrm{SD}=.59$ ) versus low (attitudes: $\mathrm{M}=5.46, \mathrm{SD}=1.04, p=.004$; intentions: $\mathrm{M}=4.28, \mathrm{SD}=.66, p=.008)$ physical contact salience. When indicators of similarity with other users were present, these differences in respondents' evaluations were mitigated between the high (attitudes: $\mathrm{M}=5.26, \mathrm{SD}=1.05$; intentions: $\mathrm{M}=4.16, \mathrm{SD}=.54$ ) and low (attitudes: $\mathrm{M}$ $=5.18, \mathrm{SD}=.98 ; p>.1$; intentions: $\mathrm{M}=4.15, \mathrm{SD}=.66 ; p>.1)$ physical contact conditions, in support of H6.

\section{[FIGURE 3 HERE]}

The main effects for physical contact salience on attitudes $\left(F(1,192)=3.25, p=.073, \omega_{p}^{2}=\right.$ $.011)$ and intentions to use $\operatorname{ABS}\left(F(1,192)=3.41, p=.066, \omega_{p}^{2}=.012\right)$ are marginally significant. In support of $\mathrm{H} 5$, participants note more negative evaluations of ABS in the high contact salience condition (attitudes: $\mathrm{M}=5.32, \mathrm{SD}=1.01$; intentions: $\mathrm{M}=4.05, \mathrm{SD}=.57$ ) than the low one (attitudes: $\mathrm{M}=5.05, \mathrm{SD}=1.07$; intentions: $\mathrm{M}=4.21, \mathrm{SD}=.66$ ). The main effects for interpersonal similarity on attitudes $(F(1,192)=.25, p>.1)$ and intentions to use $\operatorname{ABS}(F(1$, $192)=.29, p>.1)$ are not significant.

\section{Discussion}

The results of Study 4 show that when firms vividly highlight physical contacts between products and users in advertising (a traditional communication practice used by $\mathrm{ABS}$ providers), consumers whose contamination concept is activated have lower intentions to use ABS. The findings further indicate that highlighting interpersonal similarity with other users may mitigate the negative effects of physical contact depictions on consumers' evaluations, 
because other ABS users who are similar tend to be regarded as in-group members who do not pose a threat (contaminant) to the self (Reicher et al. 2016). Specifically, when similarity with other users is high, consumers no longer respond negatively to advertisements displaying a high incidence of physical contacts. It is important to note, though, that these effects may only be relevant to those consumers who have a relatively high level of contamination concerns naturally (Rozin, Haidt, and McCauley 2008) or whose contamination concepts have been unintentionally activated during the consumer journey (Bargh et al. 2001). For instance, consumers may have just seen another advertisement for a product that commonly elicits disgust (e.g., feminine napkins; Morales and Fitzsimons 2007), or just had an unpleasant experience such as smelling a noxious odor. These situations cannot be prevented by ABS providers, suggesting that they should take contamination into careful consideration when designing and using communication instruments aimed at promoting ABS adoption.

\section{GENERAL DISCUSSION}

The primary objectives of this research have been to examine experimentally (1) the impact of consumer contamination concerns on ABS evaluation, (2) when consumers experience contamination concerns about shared products, and (3) what ABS providers can do to prevent or reduce such concerns. Study 1 illustrates that contamination concerns impede the adoption of ABS, because consumers with high levels are less likely to adopt and use ABS. Study 2 shows that consumers experience more contamination concerns toward objects used in proximity to their bodies, especially when those objects are shared with unfamiliar users. According to Study 3, the higher the level of brand equity of the ABS provider, the lower consumers' contamination concerns, due to their elevated stereotype-related perceptions of the competence of other users who come into contact with the shared products. Finally, Study 4 shows that highlighting the incidence of physical contact between objects and users in 
advertising can be detrimental to ABS providers, especially when other users are not perceived as similar.

\section{Theoretical Implications}

With four studies, this article bridges several distinct research areas: ABS, innovation diffusion, and contamination. In doing so, it makes several contributions. First, it joins an emerging stream of research about consumer rejection of service innovations (Martin, Gustafsson, and Choi 2016) that highlights the importance of investigating reasons against their adoption. Prior research on ABS innovation reveals negative impacts of product scarcity, status, security, and technical costs on consumer evaluations (e.g., Claudy, Garcia, and O'Driscoll 2015; Lamberton and Rose 2012); we offer a further empirical contribution by demonstrating the negative effects of consumers' contamination concerns on their evaluations of ABS. Our findings also contribute to contamination literature (e.g., Morales, Dahl, and Argo 2018) by showing that contamination concerns negatively influence not only consumers' evaluations of products they wish to purchase and own (e.g., Argo, Dahl, and Morales 2006), but also their evaluations of objects they wish to access.

Second, we extend consumer research on negative contamination (Argo, Dahl, and Morales 2006; White et al. 2016) by specifying the influences of product-body proximity and interpersonal familiarity. Consumers tend not only to display contamination concerns about consumables (Castro, Morales, and Nowlis 2013) but also to avoid sharing tangible, nonconsumable objects associated with ingestion or food consumption. In so doing, this research reveals that mere association with ingestion is sufficient to trigger contamination concerns. Moreover, the effects of product-body proximity are even more important when the objects are shared through ABS with unfamiliar users, who are potentially threatening. We thus argue that the nature of the person who has come into contact with a product may explain not only positive contamination effects (e.g., celebrity; Newman, Diesendruck, and Bloom 2011) but also negative ones. 
Third, this study provides initial empirical evidence for how specific organizational branding practices influence consumer contamination concerns. In doing so, it contributes to the contamination literature and responds to calls for more research about firm strategies that can reduce consumer rejection of service innovations (e.g., Talke and Heidenreich 2014), especially by overcoming the contamination barrier (Hazée, Delcourt, and Van Vaerenbergh 2017). Drawing on signaling theory (Spence 1974), prior marketing research has shown that signals related to branding are effective means for overcoming consumer-perceived barriers (e.g., Corkindale and Belder 2009; Henard and Dacin 2010). This study complements this finding by showing that brand equity is another effective tactic, in terms of overcoming the contamination barrier and reducing ABS rejection. It also shows that competence stereotypes about other users serve as an underlying mechanism, providing further support for the need to consider the nature of any source that comes into contact with the object when studying negative contamination effects.

Fourth, prior research typically shows that firms' communication practices aimed at providing consumers with clear, accurate information about innovations can reduce rejection (e.g., Heidenreich and Kraemer 2016). In particular, prior studies posit that pictorial stimuli can help consumers fully understand the benefits of the service innovation and reduce consumer rejection (e.g., Rossiter and Percy 1980; Zhao, Hoeffer, and Zauberman 2011). In contrast, our findings reveal that ABS advertisements vividly depicting a high incidence of physical contact between objects and other users negatively influence evaluations by consumers whose contamination concept is activated, especially if they do not consider other ABS users similar to themselves.

\section{Managerial Implications}

Around the world, services that provide consumers with access to products are gaining ground. Despite their potential benefits to consumers, it remains challenging for service providers to convince consumers to use ABS. Firms need to understand the barriers that consumers perceive, 
so that they can develop novel and efficient rejection-reduction strategies and increase adoption rates for their offerings (Talke and Heidenreich 2014).

Consistent with prior suggestions (Hazée, Delcourt, and Van Vaerenbergh 2017), we find that concern about product contamination is a barrier to ABS use. Consumers' contamination concerns negatively influence their attitudes and intentions to adopt access offers. Overcoming the contamination barrier is thus of particular importance for service providers, and our findings indicate that firms might take three specific actions, related to their product, branding, and communication strategies, to reduce consumers' contamination concerns and the negative impacts on ABS adoption.

First, firms should be aware that contamination effects differ with the types of objects being shared. Consumers experience more contamination concerns about objects used in proximity to their bodies; tangible objects that are specifically associated with food consumption or oral ingestion are more likely to trigger these concerns. To suppress them, we recommend that firms carefully choose the objects they make available through access offers or highlight in their communications campaigns. For example, ABS providers could prioritize gardening or renovating tools over kitchen tools, in advertising, to reduce the likelihood of consumer contamination concerns and enhance the adoption rate of their services. Negative contamination effects also depend on the nature of the person who comes in contact with the shared objects. With our finding that consumers are more likely to experience contamination concerns about objects shared with unfamiliar users, we also suggest that firms should increase perceptions of familiarity with other users by encouraging a sense of identification with the community (see McAlexander, Schouten, and Koenig 2002). This option would not only meet ABS consumers' desires to be part of a community (Schaefers 2013) but also attenuate the likelihood of contamination concerns.

Second, the higher the brand equity, the lower consumers' contamination concerns, so ABS providers must develop positive brand associations that can carry over and positively 
affect consumers' perceptions of the brands' actual consumers. Branding literature underlines the importance of developing unique brand personality, reputation for high service quality, and positive brand identity (Aaker 1991). Such efforts are expensive and difficult for start-ups that wish to benefit from the sharing economy (Needleman and Loten 2014), so we recommend that firms first implement product and communications strategies that can help overcome the contamination barrier and boost adoption rates for their offerings.

Third, service providers should carefully consider consumers' contamination concerns when designing their advertising, promotions, and other communications. Vividly depicting physical contact between shared objects and other users in advertising (e.g., "One car is used by 15 different drivers!") is detrimental if consumers' contamination concept is activated. To avoid the latter undesired effects and encourage consumers whose contamination concept is activated (e.g., individuals who have a relatively high level of contamination concerns naturally) to use ABS, our results show firms should highlight the similarity of other users when advertising their access offers.

\section{Limitations and Further Research}

This study has some limitations that suggest directions for further research. First, it focuses on ABS as the research context; traditional businesses that are innovating and offering services based on access are likely to face consumer rejection. However, consumers also have increasing opportunities to opt for alternative access-based offers, such as peer-to-peer (P2P) services (Benoit et al. 2017). Accordingly, scholars could test the results of this study in different access contexts. According to the type of access, consumers' expectations about disease presence, harmfulness, and cleaning activities may vary. Researchers also could investigate when contamination becomes salient in $\mathrm{P} 2 \mathrm{P}$ settings, given the unique characteristics of these innovations (Benoit et al. 2017). Public profiles of P2P service providers may influence consumers' stereotype-related perceptions and affect their concern about product contamination, for example. 
Second, researchers could examine other ways to prevent and reduce consumers' contamination concerns. Our investigation focuses on the effects of four specific firm actions: (1) influencing familiarity perceptions with regard to other ABS users, (2) developing brand equity, (3) highlighting physical contact as well as (4) the similarity of other ABS users in advertising. Continued research could examine the effects of different types of marketing instruments, such as warranties or mental simulation (see Heidenreich and Kraemer 2016) to overcome the contamination barrier. Moreover, clinical research suggests that an efficient method for reducing patients' contamination concerns is exposure and response prevention (e.g., Rachman 2004); investigation of the effects of ABS demonstrations and trials on contamination concerns would be an interesting avenue for research.

ABS providers also often communicate with consumers about product cleaning frequency. For example, Zipcar advertises that its cars are cleaned at least once per week and that on-demand cleaning may be scheduled if a dirty car is reported. On one hand, product contamination is commonly associated with uncleanliness and dirtiness (Morales and Fitzsimons 2007), suggesting that communicating with consumers about cleaning frequency is a strategy for reducing contamination concerns. On the other hand, communicating about cleaning frequency may trigger contamination concerns, because it makes an object's close contact with other consumers more salient (Argo, Dahl, and Morales 2006). To date, however, researchers have not determined whether such communications are effective (or not) for preventing and/or reducing consumers' contamination concerns about ABS.

Third, recent studies of the diffusion of the sharing economy show that reasons to adopt such service innovations differ across cultural backgrounds (e.g., Davidson, Habibi, and Laroche 2018). Research in social psychology suggests that people's propensity to feel disgust may differ according to their cultural orientations (e.g., Rozin, Haidt, and McCauley 2008). These observations call for more research on the role of culture in affecting contamination concerns related to ABS adoption. For example, people who score high on power distance may 
be more likely to experience contamination concerns about ABS, due to their tendency to react more quickly and strongly to perceived threats (Taylor 2000).

Fourth, Study 3 controls for consumers' prior experience with ABS, and reveals no significant effect of prior experience on contamination concerns, but the majority of our respondents had no previous experience with ABS. Additional research could investigate the effects of prior experience with ABS. On the one hand, because consumers who have little or no experience with ABS may be more likely to engage in counterfactual thinking (Kahneman and Miller 1986) and compare ABS with the ideal consumption mode that is ownership (Bardhi and Eckhardt 2012), any mutable or differentiating feature, such as contamination, might be particularly salient for them. On the other hand, consumers with more experience have had opportunities to confront their fears by using the service, which may either confirm or disconfirm their contamination concerns about ABS.

Fifth, we demonstrate in Study 4 that ABS providers who vividly highlight physical contacts between products and users in advertising negatively influence ABS evaluations by consumers whose contamination concept is activated. Put differently, this effect may only be relevant to those consumers who were unintentionally exposed to contamination cues during their journey (Chartrand et al. 2008), or who have a relatively high level of contamination concerns naturally (Rozin, Haidt, and McCauley 2008). A logical next step would be to examine whether and when depiction of physical contacts with products in advertisements also triggers consumers' contamination concerns about ABS. 


\section{FOOTNOTES}

1. A follow-up study (online survey with MTurk respondents; 7 participants excluded; $N=$ $123,38.2 \%$ female, mean age $=32$ years $)$ further shows consumer contamination concerns are significantly and negatively correlated with consumer attitudes toward ABS $(r=-.379$, $p<.01)$ and intentions to use ABS $(r=-.299, p<.01)$.

2. We also asked respondents to indicate, using a binary measure, whether they had experience with similar ABS. The results of an analysis of covariance (ANCOVA) with prior experience with $\mathrm{ABS}$ as a covariate revealed that the latter did not exert any significant effect on contamination concerns $(F(1,290)=1.83, p>.1)$. Therefore, we do not include this covariate in subsequent analyses.

3. We also conducted an ANCOVA with general liking of the advertisement as a covariate, which yielded similar results. 


\section{REFERENCES}

Aaker, David A. (1991), Managing Brand Equity. New York: The Free Press.

Aaker, Jennifer, Kathleen D. Vohs, and Cassie Mogilner (2010), "Nonprofits are Seen as Warm and For-Profits as Competent: Firm Stereotypes Matter," Journal of Consumer Research, 37 (2), 224-37.

Argo, Jennifer J., Darren W. Dahl, and Andrea C. Morales (2006), “Consumer Contamination: How Consumers React to Products Touched by Others," Journal of Marketing, 70 (2), 81 94.

----, ----, and ---- (2008), 'Positive Consumer Contagion: Responses to Attractive Others in a Retail Context," Journal of Marketing Research, 45 (6), 690-701.

Bardhi, Fleura and Giana M. Eckhardt (2012), “Access-Based Consumption: The Case of Car Sharing," Journal of Consumer Research, 39 (4), 881-98.

Bargh, John A., Peter M. Gollwitzer, Annette Lee-Chai, Kimberly Barndollar, and Roman Trotschel (2001), "The Automated Will: Nonconscious Activation and Pursuit of Behavioral Goals,” Journal of Personality and Social Psychology, 81 (6), 1014-27.

Belk, Russell W. (2014), "You Are What You Can Access: Sharing and Collaborative Consumption Online," Journal of Business Research, 67 (8), 1595-1600.

Benoit, Sabine, Thomas L. Baker, Ruth N. Bolton, Thorsten Gruber, and Jay Kandampully (2017), “A Triadic Framework for Collaborative Consumption (CC): Motives, Activities, and Resources \& Capabilities of Actors," Journal of Business Research, 79 (10), 219-27.

Berger, Jonah and Chip Heath (2008), "Who Drives Divergence? Identity-Signaling, Outgroup Dissimiliarity, and the Abandonment of Cultural Tastes," Journal of Personality and Social Psychology, 95 (3), 593-607.

Brady, Michael K., J. Joseph Cronin Jr., Gavin L. Fox, and Michelle L. Roehm (2008), "Strategies to Offset Performance Failures: The Role of Brand Equity," Journal of Retailing, 84 (2), 151-64. 
Castro, Iana A., Andrea C. Morales, and Stephen M. Nowlis (2013), "The Influence of Disorganized Shelf Displays and Limited Product Quantity on Consumer Purchase," Journal of Marketing, 77 (4), 118-33.

Chartrand, Tanya L., Joel Huber, Baba Shiv, and Robin J. Tanner (2008), "Nonconscious Goals and Consumer Choice," Journal of Consumer Research, 35 (2), 189-201.

Claudy, Marius C., Rosanna Garcia, and Aidan O'Driscoll (2015), “Consumer Resistance to Innovation - A Behavioral Reasoning Perspective," Journal of the Academy of Marketing Science, 43 (4), 528-44.

Corkindale, David and Marcus Belder (2009), "Corporate Brand Reputation and the Adoption of Innovations," Journal of Product and Brand Management, 18 (4), 242-50.

Crump, Matthew J. C., John V. McDonnell, and Todd M. Gureckis (2013), "Evaluating Amazon's Mechanical Turk as a Tool for Experimental Behavioral Research," PLoS ONE, $8(3), 1-18$.

Dabholkar, Pratibha A. and Richard P. Bagozzi (2002), “An Attitudinal Model of TechnologyBased Self-Service: Moderating Effects of Consumer Traits and Situational Factors," Journal of the Academy of Marketing Science, 30 (3), 184-201.

Darke, Peter R. and Robin J.B. Ritchie (2007), "The Defensive Consumer: Advertising Deception, Defensive Processing, and Distrust," Journal of Marketing Research, 44 (1), $114-27$.

Davidson, Alexander, Mohammad Reza Habibi, and Michel Laroche (2018), "Materialism and the Sharing Economy: A Cross-Cultural Study of American and Indian Consumers," Journal of Business Research, 82 (1), 364-72.

Desai, Kalpesh K. and Kevin L. Keller (2002), “The Effects of Ingredient Branding Strategies on Host Brand Extendibility," Journal of Marketing, 66 (1), 73-93. 
Dong, Beibei, K. Sivakumar, Kenneth R. Evans, and Shaoming Zou (2015), "Effect of Customer Participation on Service Outcomes: The Moderating Role of Participation Readiness," Journal of Service Research, 18 (2), 160-76.

Doyen, Stéphane, Olivier Klein, Cora-Lise Pichon, and Axel Cleeremans (2012), "Behavioral Priming: It's All in the Mind, but Whose Mind?" PLoS ONE, 7 (1), 1-7.

Dubé, Laurette and Bernd H. Schmitt (1999), “The Effect of a Similarity versus Dissimilarity Focus in Positioning Strategy: The Moderating Role of Consumer Familiarity and Product Category," Psychology \& Marketing, 16 (3), 211-224.

Edwards, Steven M., Jin Kyun Lee, and Carrie La Ferle (2009), "Does Place Matter When Shopping Online? Perceptions of Similarity and Familiarity as Indicators of Psychological Distance," Journal of Interactive Advertising, 10 (1), 35-50.

Fennis, Bob M. and Ad Th. H. Pruyn (2007), "You Are What You Wear: Brand Personality Influences on Consumer Impression Formation," Journal of Business Research, 60 (6), 634-39.

Fiske, Susan T., Amy J. C. Cuddy, Peter Glick, and Jun Xu (2002), “A Model of (Often Mixed) Stereotype Content: Competence and Warmth Respectively Follow from Perceived Status and Competition," Journal of Personality and Social Psychology, 82 (6), 878-902.

Frazer, James George ([1890] 1959), The New Golden Bough: A Study in Magic and Religion, abridged, T. H. Gaster, ed. New York: Macmillan.

Goldsmith, Ronald E., Barbara A. Lafferty, and Stephen J. Newell (2000), “The Impact of Corporate Credibility and Celebrity Credibility on Consumer Reactions to Ads and Brands," Journal of Advertising, 29(3), 43-54.

Goode, Miranda R., Darren W. Dahl, and Page C. Moreau (2013), "Innovation Aesthetics: The Relationship Between Category Cues, Categorization Certainty, and Newness Perceptions," Journal of Product Innovation Management, 30 (2), 192-208. 
Goodman, Joseph K. and Gabriele Paolacci (2017), "Crowdsourcing Consumer Research,” Journal of Consumer Research, 44 (1), 196-210.

Grandey, Alicia, Glenda Fisk, Anna Mattila, Karen Jansen, and Lori Sideman (2005), "Is 'Service with a Smile' Enough? Authenticity of Positive Displays during Service Encounters," Organizational Behavior and Human Decision Processes, 96 (1), 38-55.

Greenwald, Anthony G. and Mahzarin R. Banaji (1995), "Implicit Social Cognition: Attitudes, Self-Esteem and Stereotypes," Psychological Review, 102 (1), 4-27.

Griskevicius, Vladas and Douglas T. Kenrick (2013), "Fundamental Motives: How Evolutionary Needs Influence Consumer Behavior," Journal of Consumer Psychology, 23 (3), 372-86.

Gullstrand Edbring, Emma, Matthias Lehner, and Oksana Mont (2016), "Exploring Consumer Attitudes to Alternative Models of Consumption: Motivations and Barriers," Journal of Cleaner Production, 123 (1), 5-15.

Hayes, Andrew F. (2013), An Introduction to Mediation, Moderation, and Conditional Process Analysis: A Regression-Based Approach. New York: Guilford Press.

Hauser, David J., Ellsworth, Phoebe C., and Richard Gonzalez (2018), “Are Manipulation Checks Necessary?," Frontiers in Psychology, 9, 998-1008.

Hazée, Simon, Cécile Delcourt, and Yves Van Vaerenbergh (2017), "Burdens of Access: Understanding Customer Barriers and Barrier-Attenuating Practices in Access-Based Services," Journal of Service Research, 20 (4), 441-56.

Heidenreich, Sven and Matthias Handrich (2015), "What About Passive Innovation Resistance? Investigating Adoption-Related Behavior from a Resistance Perspective," Journal of Product Innovation Management, 32 (6), 878-903.

---- and Tobias Kraemer (2016), "Innovations-Doomed to Fail? Investigating Strategies to Overcome Passive Innovation Resistance," Journal of Product Innovation Management, $33(3), 277-97$. 
Henard, David H. and Peter A. Dacin (2010), "Reputation for Product Innovation: Its Impact on Consumers," Journal of Product Innovation Management, 27 (3), 321-35.

Hill, Donna J., Jeff Blodgett, Robert Baer, and Kirk Wakefield (2004), “An Investigation of Visualization and Documentation Strategies in Services Advertising," Journal of Service Research, 7 (2), 155-66.

Kahneman, Daniel and Dale T. Miller (1986), "Norm Theory: Comparing Reality to its Alternatives," Psychological Review, 93 (2), 136-53.

Kapitan, Sommer and Rajesh Bhargave (2013), "Navigating Residue Sensitivity in the Used Goods Marketplace," Psychology and Marketing, 30 (4), 305-17.

Kotler, Philip and Murali K. Mantrala (1985), "Flawed Products: Consumer Responses and Marketer Strategies," Journal of Consumer Marketing, 2 (3), 27-36.

Krishnan, H. Shanker (1996), "Characteristics of Memory Associations: A Consumer-Based Brand Equity Perspective," International Journal of Research in Marketing, 13 (4), 389405.

Lamberton, Cait Poynor and Randall R. Rose (2012), "When Is Ours Better Than Mine? A Framework for Understanding and Altering Participation in Commercial Sharing Systems," Journal of Marketing, 76 (4), 109-25.

Lawson, Stephanie J., Mark R. Gleim, Rebecca Perren, and Jiyoung Hwang (2016), "Freedom from Ownership: An Exploration of Access-Based Consumption," Journal of Business Research, 69 (8), 2615-23.

Liviatan, Ido, Yaacov Trope, and Nira Liberman (2008), "Interpersonal Similarity as a Social Distance Dimension: Implications for Perception of Others' Actions," Journal of Experimental Social Psychology, 44 (5), 1256-69.

Martin, Drew, Anders Gustafsson, and Sunmee Choi (2016), "Service Innovation, Renewal, and Adoption/Rejection in Dynamic Global Contexts," Journal of Business Research, 69 (7), 2397-400. 
Maxham III, James G. and Richard G. Netemeyer (2002), "A Longitudinal Study of Complaining Customers' Evaluations of Multiple Service Failures and Recovery Efforts,” Journal of Marketing, 66 (4), 57-71.

McAlexander, James H., John W. Schouten, and Harold F. Koenig (2002), "Building Brand Community," Journal of Marketing, 66 (1), 38-54.

Morales, Andrea C. and Gavan J. Fitzsimons (2007), "Product Contagion: Changing Consumer Evaluations Through Physical Contact with 'Disgusting' Products," Journal of Marketing Research, 44 (2), 272-83.

----, Darren W. Dahl, and Jennifer J. Argo (2018), “Amending the Law of Contagion: A General Theory of Property Transference," Journal of the Association of Consumer Research, 3 (4), 555-65.

Moreland, Richard L. and Robert B. Zajonc (1982), "Exposure Effects in Person Perception: Familiarity, Similarity, and Attraction," Journal of Experimental Social Psychology, 18 (5), 395-415.

Needleman, Sarah E. and Angus Loten (2014), "Startups Want to Be the Next Airbnb, Uber," The Wall Street Journal, (May 7), (accessed May 21, 2016), [available at http://www.wsj.com/articles/SB10001424052702303417104579546273413969150].

Nemeroff, Carol and Paul Rozin (1994), “The Contagion Concept in Adult Thinking in the United States: Transmission of Germs and of Interpersonal Influence,” Ethos, 22 (2), 15886.

Newman, George E., Gil Diesendruck, and Paul Bloom (2011), "Celebrity Contagion and the Value of Objects," Journal of Consumer Research, 38 (2), 215-28.

Oliver, Richard L. and William O. Bearden (1985), "Crossover Effects in the Theory of Reasoned Action: A Moderating Influence Attempt," Journal of Consumer Research, 12 (3), 324-40. 
Parasuraman, A., Valarie A. Zeithaml, and Leonard L. Berry (1985), “A Conceptual Model of Service Quality and Its Implications for Future Research,” Journal of Marketing, 49 (4), 41-50.

Pechman, Cornelia and Susan J. Knight (2002), “An Experimental Investigation of the Joint Effects of Advertising and Peers on Adolescents' Beliefs and Intentions about Cigarette Consumption," Journal of Consumer Research, 29 (1), 5-19.

Perdue, Barbara C. and John O. Summers (1986), "Checking the Success of Manipulations in Marketing Experiments," Journal of Marketing Research, 23 (4), 317-326.

Rachman, Stanley (2004), "Fear of Contamination," Behaviour Research and Therapy, 42 (11), $1227-55$.

Reicher, Stephen D., Anne Templeton, Fergus Neville, Lucienne Ferrari, and John Drury (2016), “Core Disgust is Attenuated by Ingroup Relations," PNAS, 113 (10), 2631-35.

Rossiter, John R. and Larry Percy (1980), “Attitude Change through Visual Imagery in Advertising," Journal of Advertising Research, 9 (2), 10-16.

Rozin, Paul, and April E. Fallon (1987), “A Perspective on Disgust,” Psychological Review, 94 (1), 23-41.

----, Jonathan Haidt, and Clark McCauley (2008), "Disgust," in Handbook of Emotions, M. Lewis, J. M. Haviland-Jones, and L.F. Barrett, eds. New York: Guilford Press.

Schaefers, Tobias (2013), “Exploring Car-Sharing Usage Motives: A Hierarchical Means-End Chain Analysis," Transportation Research Part A, 47, 69-77.

----, Kristina Wittkowski, Sabine Benoit, and Rosellina Ferraro (2016), “Contagious Effects of Customer Misbehavior in Access-Based Services," Journal of Service Research, 19 (1), 3 21.

Sharpe Wessling, Kathryn, Joel Huber, and Oded Netzer (2017), "MTurk Character Misrepresentation: Assessment and Solutions," Journal of Consumer Research, 44 (1), 211-230. 
Spence, Michael A. (1974), Market Signaling: Informational Transfer in Hiring and Related Screening Processes. Cambridge: Harvard University Press.

Stein, Joel (2015), "Strangers Crashed My Car, Ate My Food and Wore My Pants—Tales from the Sharing Economy," Time, 185 (4), 1-60.

Talke, Katrin and Sven Heidenreich (2014), "How to Overcome Pro-Change Bias: Incorporating Passive and Active Innovation Resistance in Innovation Decision Models," Journal of Product Innovation Management, 31 (5), 894-907.

Taylor, Kathleen (2007), "Disgust is a Factor in Extreme Prejudice," British Journal of Social Psychology, 46 (3), 597-617.

Taylor, Maureen (2000), “Cultural Variance as a Challenge to Global Public Relations: A Case Study of the Coca-Cola Scare in Europe," Public Relations Review, 26 (3), 277-93.

Turner, John C., Michael A. Hogg, Penelope J. Oakes, Stephen D. Reicher, and Margareth S. Wetherell (1987), Rediscovering the Social Group: A Self-Categorization Theory. New York: Basil Blackwell.

Tylor, Edward Burnett ([1871] 1974), Primitive Culture: Researches into the Development of Mythology, Philosophy, Religion, Art, and Custom. New York: Gordon Press.

White, Katherine, Lily Lin, Darren W. Dahl, and Robin J. B. Ritchie (2016), "When Do Consumers Avoid Imperfections? Superficial Packaging Damage as a Contamination Cue," Journal of Marketing Research, 53 (1), 110-23.

Zhao, Min, Steve Hoeffer, and Gal Zauberman (2011), "Mental Simulation and Product Evaluation: The Affective and Cognitive Dimensions of Process Versus Outcome Simulation," Journal of Marketing Research, 48 (5), 827-39. 
Figure 1: Conceptual Framework

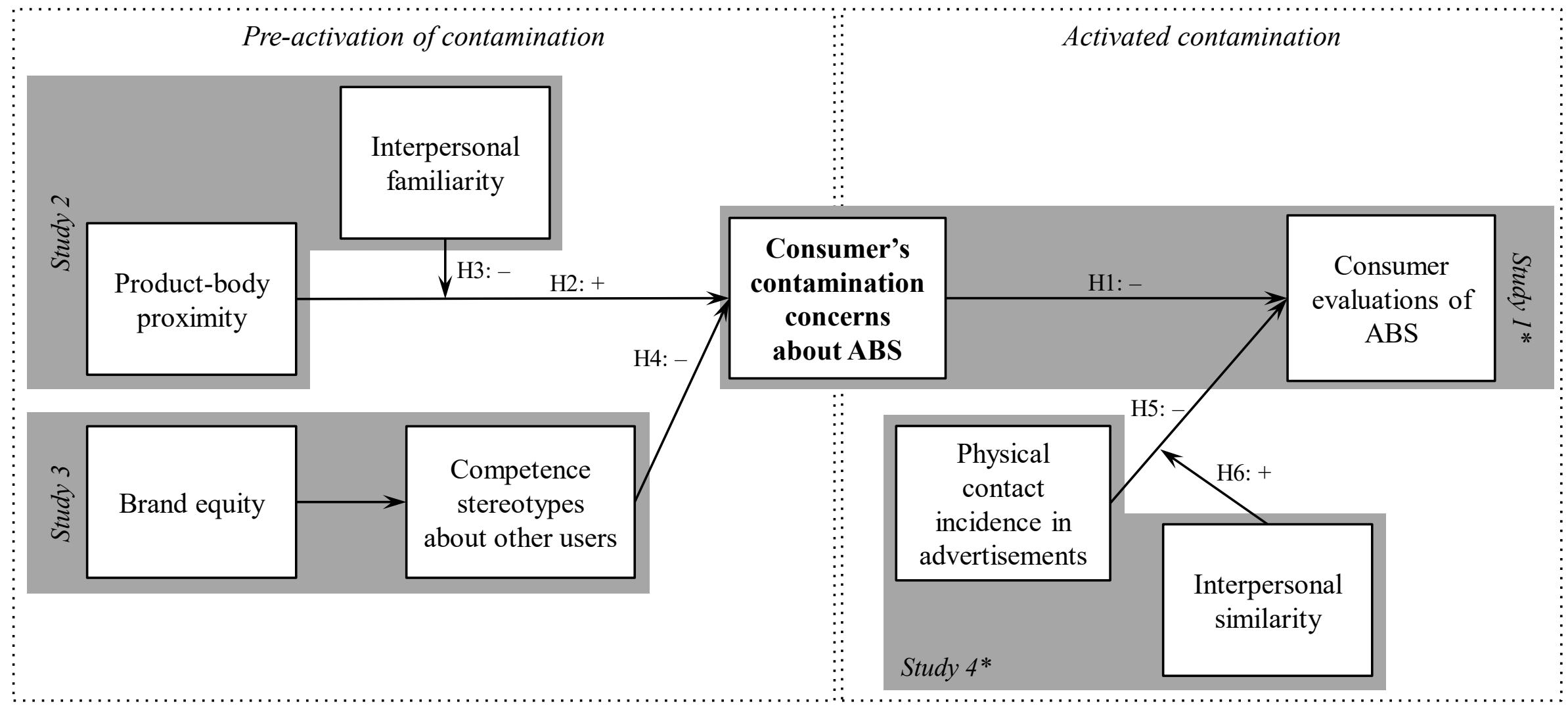

Notes. ABS $=$ Access-Based Services. * In Study 1 and Study 4, contamination is primed rather than measured. 
Figure 2: Consumers' Contamination Concerns in ABS as a Function of Product-Body Proximity and Interpersonal Familiarity (Study 2)

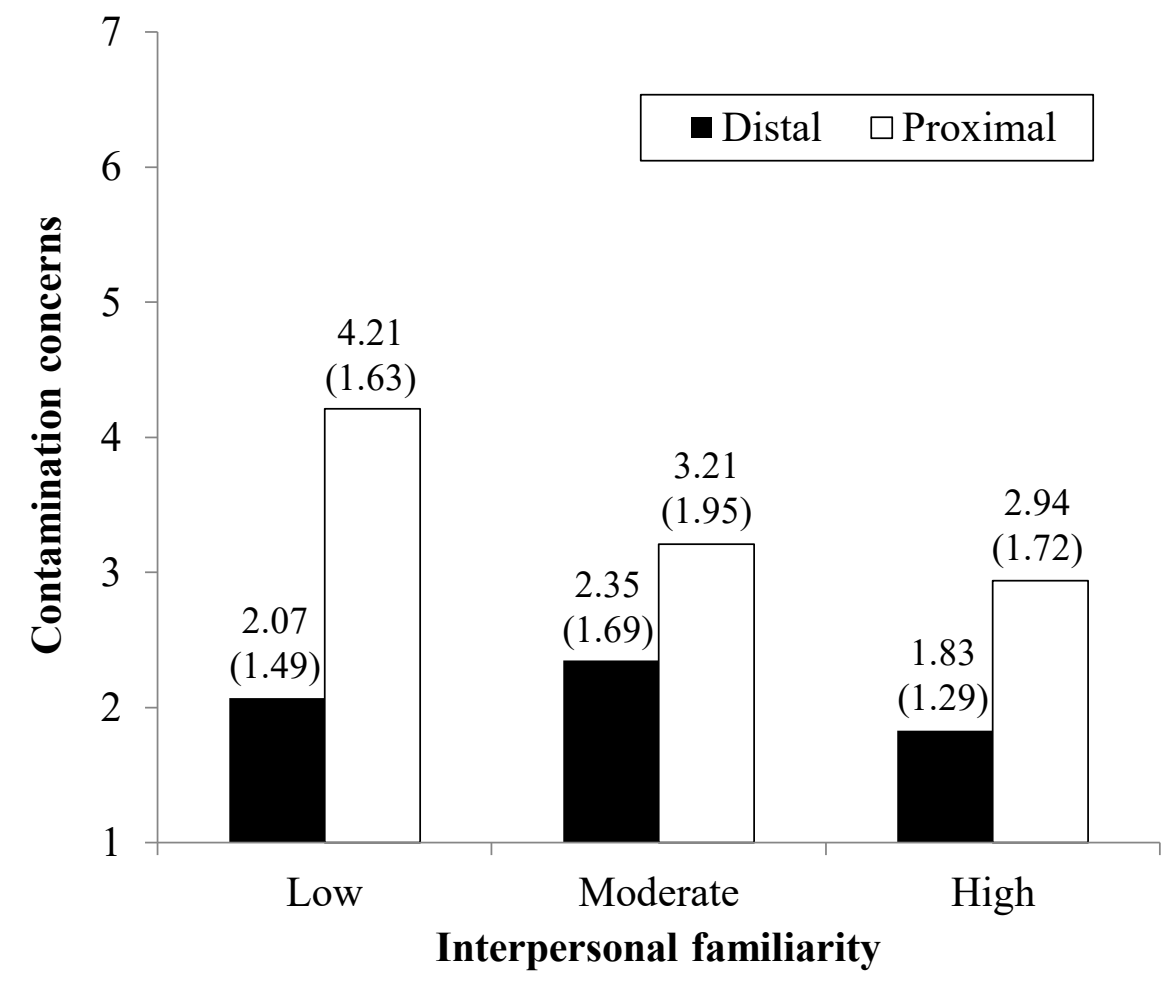

Note. Mean values (standard deviation). 
Figure 3: Consumer Evaluations of ABS as a Function of Physical Contact Incidence and Interpersonal Similarity (Study 4)

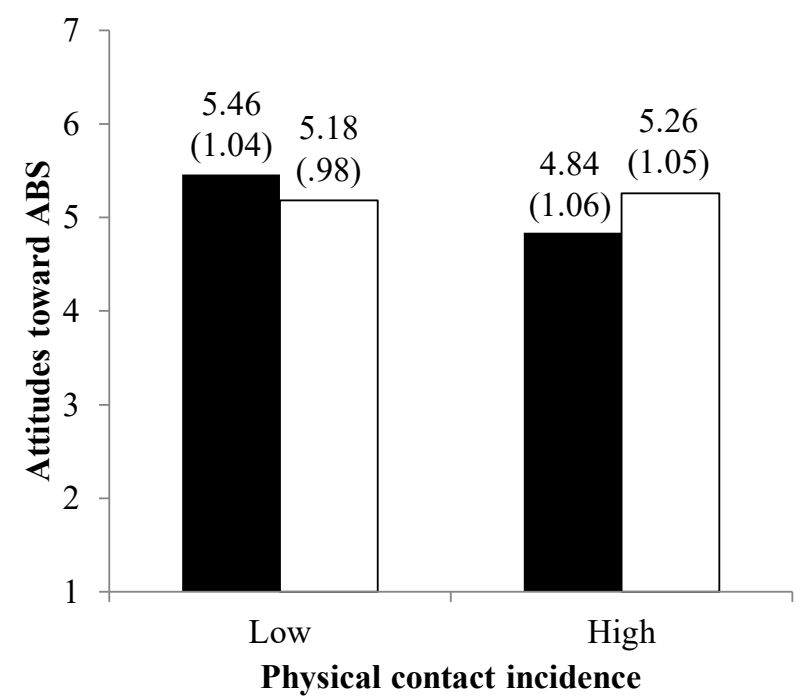

Note. Mean values (standard deviation).

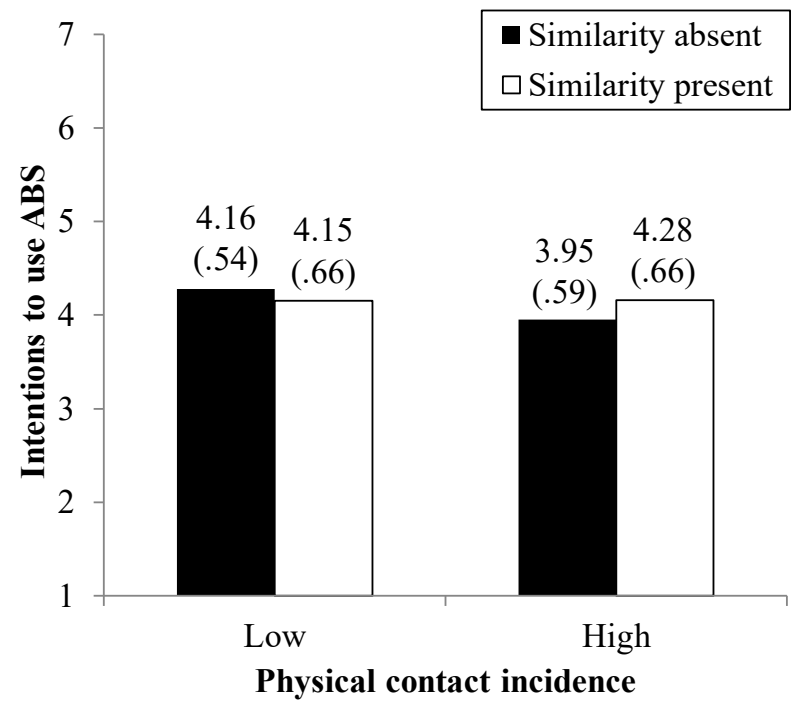

Physical contact incidence 


\section{WEB APPENDIX}

\section{Explanations about the sample size calculations (used in all studies)}

Given the reproducibility issues faced in numerous research areas (see Munafò et al. 2017), we decided to perform sample size calculation before collecting data to ensure our samples have enough statistical power. The statistical power of a study depends on the strength of the effect size, the $\alpha$ level, and the sample size (Ellis 2010). Researchers thus can calculate up front the required sample size to reliably find and interpret a certain effect size. Because there was no prior research testing the specific set of hypotheses that we formulated in this paper, we anticipated for all studies a medium effect size $(r=.30)$. We also used a .80 statistical power level (Krzywinski and Altman 2013) and the conventional .05 $\alpha$ level as inputs. All sample size calculations were performed using $\mathrm{G}^{*}$ Power 3.1.6 (Faul et al. 2007).

\section{Description of a typical car-sharing service (used in Study 1 and Study 4)}

Adapted from both the website of a popular car-sharing program and the car-sharing description developed by Lamberton and Rose (2012):

Car-sharing companies typically operate in large cities. They offer a fleet of vehicles that are available at numerous stations (reserved parking slots), spread all over the cities. To use the car-sharing system, you first need to subscribe and then pay membership and usage fees (depending on the number of kilometers traveled and your reservation periods). Everything is included: gasoline, parking fees, and insurance.

As a consumer, you can book a car by phone (thanks to a mobile application) and/or via the Internet, 7 days a week and 24h per day, for any duration of your choice. The reservations can either be done at the last minute or weeks in advance. Once the car is reserved, you just need to go to the station where the previous user left the car (within 7 minutes walking time maximum), unlock it using your membership card, and use it to your needs during the reservation period. Afterwards, you need to drop the car back to the initial station; all without any contact with employees or previous users. 


\section{WEB APPENDIX}

(continued)

\section{Stimuli used in Study 4}

Advertisement used in the high contact incidence and similarity present condition:

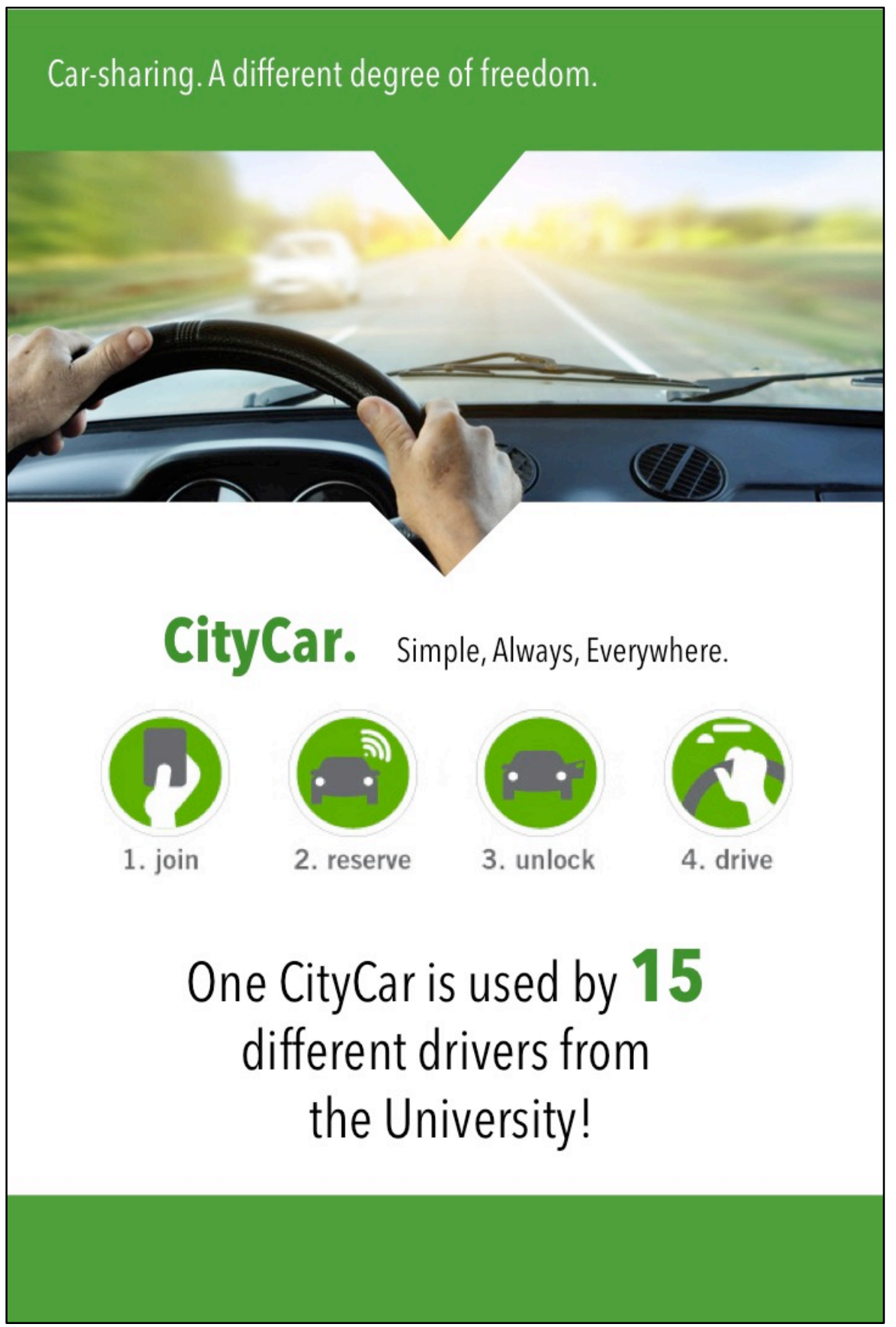




\section{WEB APPENDIX}

(continued)

Advertisement used in the high contact incidence and similarity absent condition:

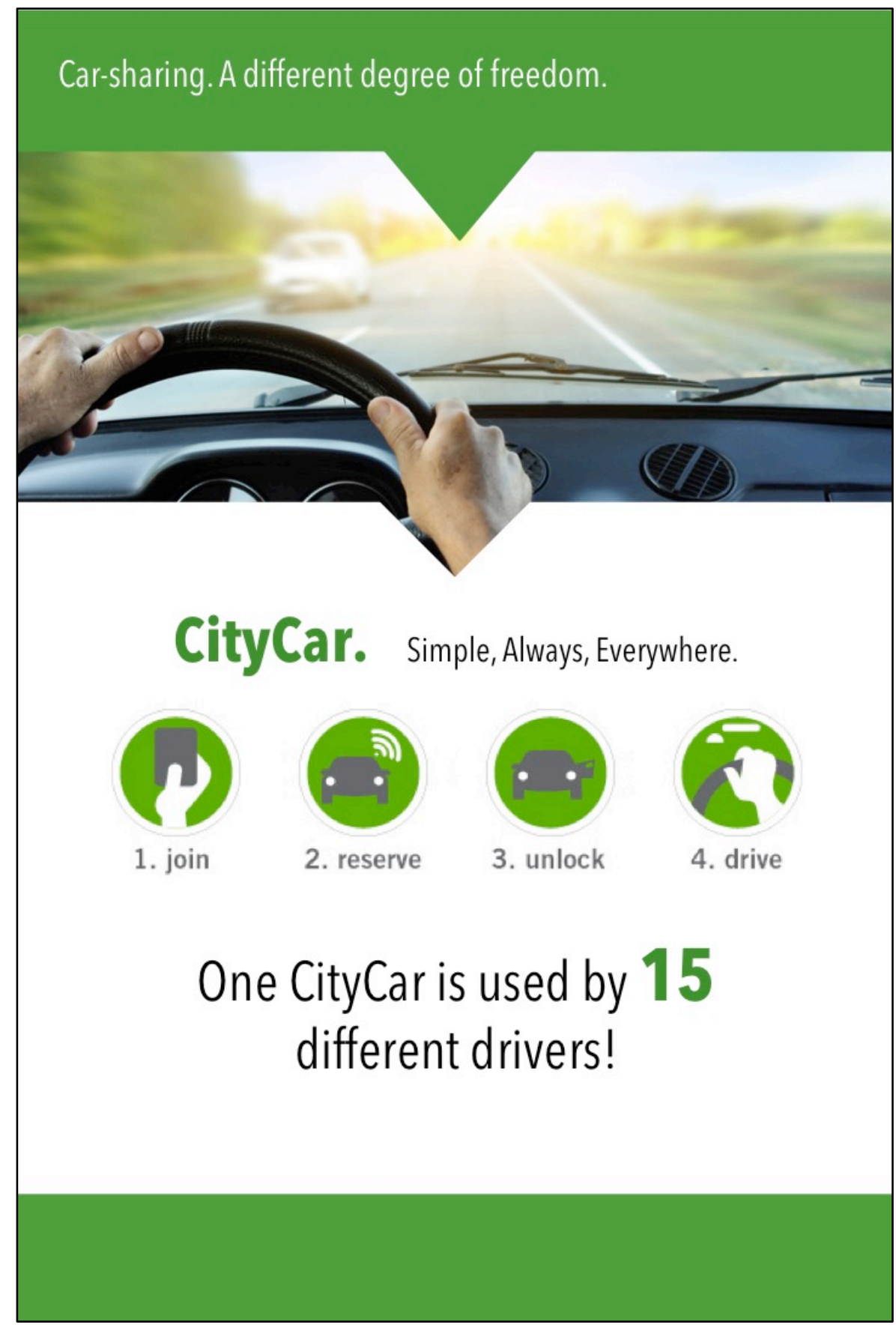




\section{WEB APPENDIX}

(continued)

Advertisement used in the low contact incidence and similarity absent condition:

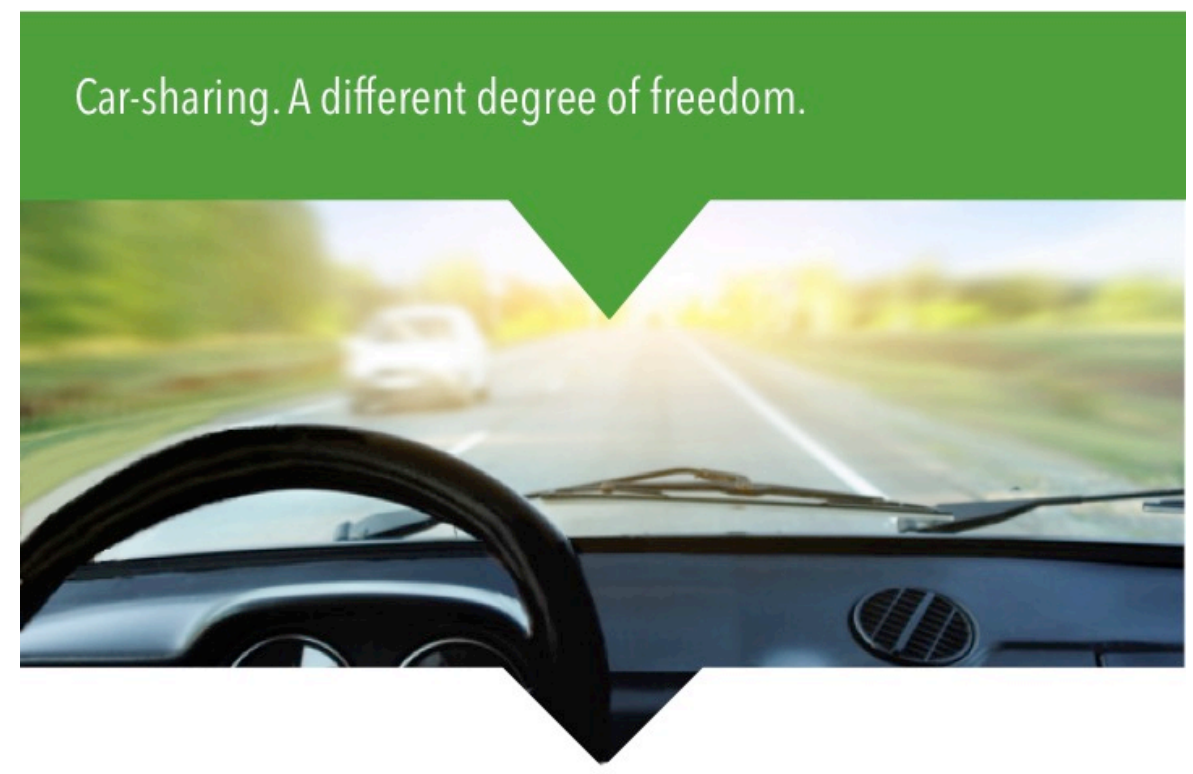

CityCar. Simple, Always, Everywhere.
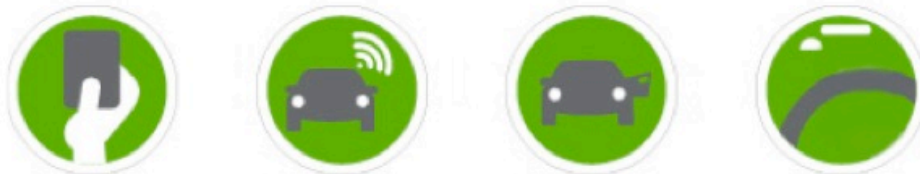

1. join

2. reserve

3. unlock

4. drive 


\section{WEB APPENDIX}

(continued)

Advertisement used in the low contact incidence and similarity present condition:

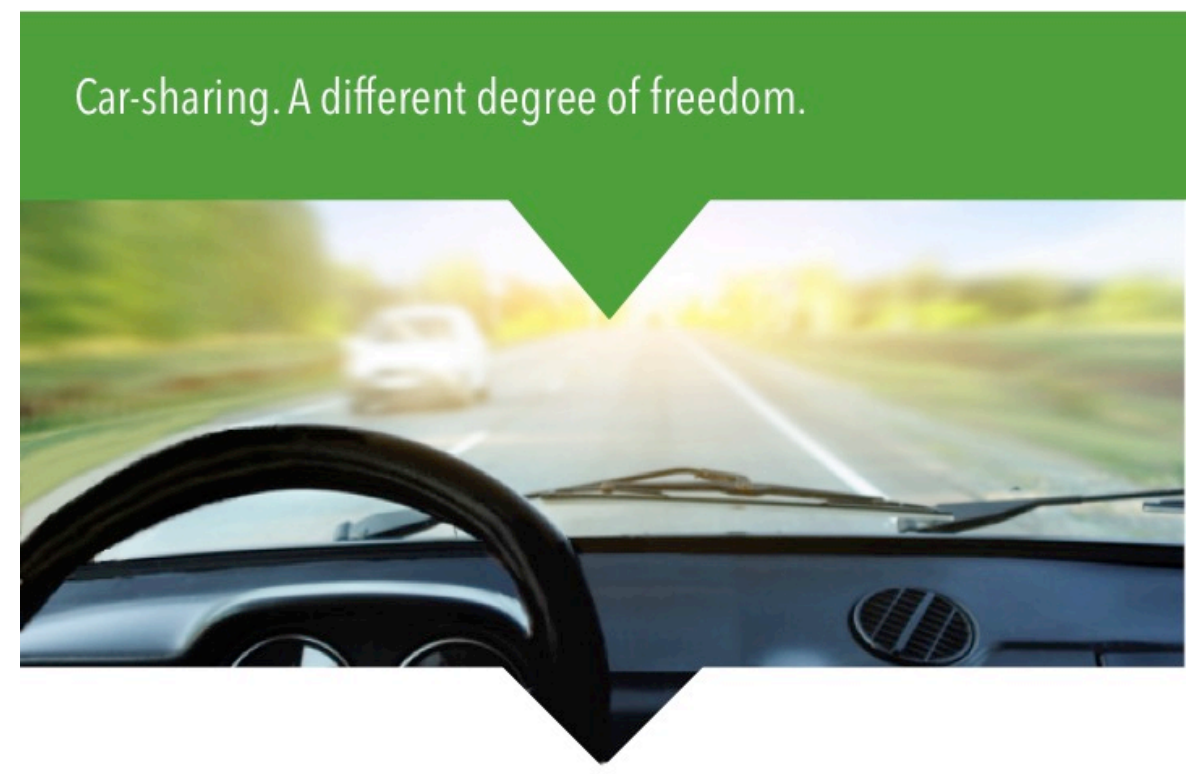

CityCar. Simple, Always, Everywhere.
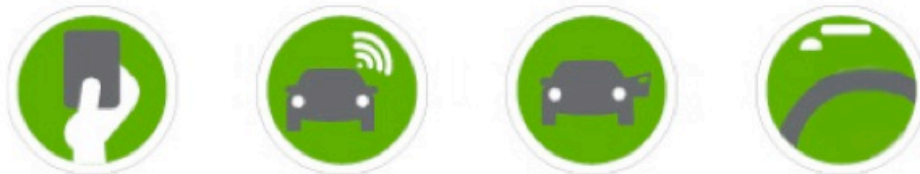

1. join

2. reserve

3. unlock

4. drive 


\section{WEB APPENDIX}

(continued)

\section{References used in the Web Appendix:}

Ellis, Paul D. (2010), The Essential Guide to Effect Sizes: Statistical Power, Meta-Analysis, and the Interpretation of Research Results, Cambridge: Cambridge University Press.

Faul, Franz, Edgar Erdfelder, Albert-Georg Lang, and Axel Buchner (2007), "G*Power 3: A Flexible Statistical Power Analysis Program for the Social, Behavioral, and Biomedical Sciences," Behavior Research Methods, 39(2), 175-91.

Krzywinski, Martin and Naomi Altman (2013), "Points of Significance: Power and Sample Size," Nature: Methods, 10(12), 1139-40.

Munafò, Marcus R., Brian A. Nosek, Dorothy V. M. Bishop, Katherine S. Button, Christopher D. Chambers, Nathalie Percie du Sert, Uri Simonsohn, Eric-Jan Wagenmakers, Jennifer J. Ware, and John P. A. Ioannidis (2017), "A Manifesto for Reproducible Science," Nature: Human Behaviour, 1(1), 1-9. 


\section{EXECUTIVE SUMMARY}

\section{Sharing Goods? Yuck, No! An Investigation of Consumers' Contamination Concerns About Access-Based Services}

Around the world, services that provide consumers with access to products are gaining ground. Typical examples include car-, bike-, and tool-sharing programs. Despite their potential benefits, it remains challenging for service providers to convince consumers to use access-based services. Among the obstacles to the adoption of such services, fear of contamination is considered as a major barrier. "Consumers may indeed experience feelings of disgust when sharing goods, which negatively influence their evaluations of the service" says the lead author Simon Hazée (HEC Liège). Together with his co-authors Yves Van Vaerenbergh (KU Leuven), Cécile Delcourt (HEC Liège), and Luk Warlop (BI Norwegian Business School), he was wondering when consumers experience contamination concerns about access-based services as well as how to prevent and overcome them.

The results from several experimental studies provide firms with new insights into these critical questions. First, consumers experience more contamination concerns about objects used in proximity to their bodies, such as tangible objects associated with food consumption or oral ingestion. Firms should therefore carefully choose the objects they make available through access offers or highlight in their communications campaigns. For example, firms could prioritize gardening or renovating tools over kitchen tools, in advertising, to reduce the likelihood of consumer contamination concerns. Negative contamination effects also depend on the nature of the person who comes in contact with the shared objects. The finding that consumers are more likely to experience contamination concerns about objects shared with unfamiliar users, suggests that firms should increase perceptions of familiarity with other users by encouraging a sense of identification with the community.

Second, the study finds that consumers' contamination concerns are reduced with higher brand equity. Firms providing access offers should develop positive brand associations that can carry over and positively affect consumers' perceptions of the brands' current customers. Developing unique brand personality, reputation for high service quality, and positive brand identity would specifically help firms overcome the contamination barrier and boost adoption rates for their access-based service offerings.

Third, service providers should carefully consider consumers' contamination concerns when designing their advertising and promotions. While it is a common practice for firms, vividly depicting physical contact between shared objects and other users in advertising is detrimental if consumers' contamination concept is activated. To avoid the latter undesired effects and encourage consumers whose contamination concept is activated (e.g., individuals who have a relatively high base level of contamination concerns) to use access-based services, the results show firms should highlight the similarity of other users when advertising their offers. Why is that so? "Well because other consumers who are similar tend to be regarded as in-group members who do not pose a threat to the self" says Simon Hazée.

In sum, this new study reveals that firms might take specific actions, related to their product, branding, and communication strategies, to reduce consumers' contamination concerns and the negative impacts on adoption of access-based services. 